\title{
Serebral palside diz problemleri
}

\author{
Knee problems in cerebral palsy
}

\author{
Cemil Yıldız ${ }^{1}$ Bülent Elbasan² \\ 1SBÜ Gülhane Tıp Fakültesi, Ortopedi ve Travmatoloji Anabilim Dalı, Ankara \\ ${ }^{2}$ Gazi Üniversitesi, Sağlık Bilimleri Fakültesi Fizyoterapi ve Rehabilitasyon Bölümü, Ankara
}

\begin{abstract}
Serebral palsili çocuklarda diz problemleri yaşamın erken dönemlerinden başlayarak motor performansı etkileyen önemli bir sorundur. Dizi çevreleyen kasların çoğunun iki eklemi geçmeleri nedeni ile, genellikle çok seviyeli problem olarak ele alınmalıdır. Hamstring kaslarındaki kısalmaya bağlı olarak bükük diz yürüyüşü görülürken, rektus femoris kasındaki kısalma gergin diz yürüyüşünün nedeni olarak bilinir. Erken dönemde kaslardaki gerginlik ve kısalmaların kontrol altına alınması, eklem hareket açıklıklarının korunması, kas kuvvetinin restorasyonu, enerji tüketiminin azaltılması, günlük yaşamda bağımsızlığın sağlanması ve yaşam kalitesinin arttırılması tedavinin temel hedefleridir. Erken dönemde daha çok fizyoterapi ve rehabilitasyon, botilinum toksin uygulamaları ve medikal yaklaşımlarla duyusal ve motor beceriler korunmaya ve geliştirilmeye çalışılırken, ilerleyen dönemlerde ortaya çıkan ikincil kas iskelet problemleri için cerrahi yöntemlerden yararlanılır. Başarılı bir tedavi için dizdeki patolojik mekanizmalar tam olarak anlaşılmalı ve doğru kas iskelet sistemi değerlendirme ve muayene yöntemleri ile bireye uygun tedavi programı oluşturulmalıdır.
\end{abstract}

Anahtar sözcülkler: serebral palsi; diz problemleri; diz ağrısı; fizyoterapi; ortopedi; diz fleksiyon kontraktürü; bükük diz; sıçrama yürüyüşü
Knee problems which affect the motor performance are very essential starting from the early stages of life in cerebral palsy. The surrounding muscles of knee are composed of two-joint muscles, therefore all knee joint disorders should be regarded as multi-level problems. The etiology of crouch gait in CP is the shortening of hamstring whereas the reason for the stiff knee gait is the stiffness in rectus femoris muscle. The aim of the treatment is controlling the muscle tension and shortening, improving the range of motion, restoration of the muscle strength, decreasing the energy consumption, improving the independency in the daily living activities and the quality of life. Physiotherapy and rehabilitation, botox injections and medications are some of the options for preserving and improving sensory and motor functions at the early stages; whereas, surgical methods are used in the secondary musculoskeletal problems later on. For successful treatment, the pathological mechanisms should be fully understood, and individualized treatment plans should be prepared with correct musculoskeletal assessments and examinations.

Key words: cerebral palsy; knee problems; knee pain; physiotherapy; orthopedics; knee flexion contracture; crouch gait; jump gait erebral palsi (SP); doğum öncesi, doğum sırası veya doğum sonrası beyinde oluşan bir lezyon nedeniyle ortaya çıkan nöromusküler bir bozukluktur. Çocukluk döneminde oldukça yaygın görülen ve engellilik oluşturan bir tablodur. ${ }^{[1,2]}$ Çocuk, merkezi sinir sistemindeki bir lezyon ile gelişmek zorunda olduğu için fiziksel problemler yaşam boyu devam etmekle birlikte, fonksiyonel kısıtlanmalar büyüme ve gelişme sürecinde değişkenlik gösterir. ${ }^{[3-5]}$ SP'li çocuklarda görülen anormal kas tonusu, kas zayıflıkları, postüral kontrol yetersizlikleri, primitif refleks paternleri, atipik kas hareketleri motor problemlere neden olmaktadır. Bu nedenlerle SP'li çocuklarda oturma, emekleme, yürüme gibi motor aktivitelerde yetersizlikler görülür. ${ }^{[6-9]}$

SP'li bireylerde diz izole bir eklem olarak düşünülmez. Özellikle diz eklemini hareket ettiren kaslara bakıldığında, arkada gastroknemius ve hamstring, önde ise rektus femoris gibi genellikle çift eklem kateden kaslar olduğundan, dizin kalça ve ayak - ayak bileği eklemi ile de bağlantısı olduğu düşünülmelidir. Bu nedenle, diz problemlerinin varlığında birden çok seviyede etkilenim olabileceği ve bu durumun duruş ve hareketi etkileyeceği bilinmelidir.

- Illetişim adresi: Prof. Dr. Cemil Yıldız, SBÜ Gülhane Tıp Fakültesi, Ortopedi ve Travmatoloji Anabilim Dalı, Ankara Tel: 0312 - 3045501 e-posta: cyorto@yahoo.com

- Geliș tarihi: 1 Ekim $2018 \quad$ Kabul tarihi: 1 Ekim 2018 
SP'li bireylerde sıklıkla görülen diz problemleri: bükük diz yürüyüşü, sıçrama yürüyüşü, gergin diz yürüyüşü, fleksiyon veya ekstansiyon problemleri ile patellofemoral eklemin dizilimindeki bozukluklar olarak bilinir. Görülen bu problemler, hem statik hem de dinamik değerlendirmelerle ortaya konabilir. Alt ekstremitlerde görülen kas zayıflığı, selektif nöronal yetersizliğe bağlı olarak ortaya çıkan spastisite, fonksiyonel bozukluklara neden olduğu gibi, yumuşak doku ve kemik dokuda oluşabilecek deformiteler için hazırlayıcı faktör olarak bilinir.

\section{Diz Fleksiyon Deformitesi}

SP'li bireylerde en sık görülen deformitelerden birisidir. Kaslarda görülen yapısal kısalmalar ve kontraktür, duruşu ve yürüyüşü olumsuz yönde etkiler. Zaman içerisinde kontrol altına alınmayan problemler, tibia tüberkülünde ve patellada kırıklara neden olur; bunun sonucunda, kalça fleksiyonunda ve lumbal lordozda artış, ayakta ekin deformitesi görülebilir. Kısalan hamstring kasları oturma postürünü etkileyerek torakal kifozun artmasına neden olur ve solunum fonksiyonları olumsuz yönde etkilenebilir.

\section{Diz Ekstansiyon Deformitesi -Genu Rekurvatum}

SP'li bireylerde, duruş fazında dizde hiperekstansiyon sıkılıkla görülen bozukluklardan birisidir. Triseps surae kasındaki spastisite veya zayıflık, Aşil tendonunda kontraktür, kuadriseps kasındaki spastisite ile birlikte gövdenin öne eğilmesi, proksimal tibida görülen deformiteler, dizdeki ligamentöz veya kapsüler laksite, hamstring grubu kaslardaki zayıflık veya bazen hamstringlerin distal uzatılması rekurvatumun nedenleri arasında sayılabilir. ${ }^{[10-17]}$ Dizde görülen rekurvatum eksternal, ekstansör moment yaratarak kapsüler ve ligamentöz yapıların yaralanmasına neden olur. ${ }^{[10,11]}$. Büyüme sırasında kontrol altına alınmayan rekurvatum zaman içerisinde instabiliteye neden olur.

\section{Bükük Diz Yürüyüşü (Crouch Gait)}

Özellikle diplejik SP'de en sık karşılaşılan yürüyüş bozukluklarından birisidir. Duruş fazında ayak - ayak bileğinde dorisfleksiyon, dizde ve kalçada artmış fleksiyon açısı ile seyreder. Rozumalski ve ark. ${ }^{[17]}$ duruş fazında dizde gördükleri armış fleksiyonun yürüyüşe olan etkisini beş grupta sınıflandırmışlardır:

- Hafif ekin ile seyir eden hafif bükük diz.

- Orta şiddette bükük diz.

- Anterior pelvik tilt ile birlikte görülen orta şiddette bükük diz.

- Ekin ile seyir eden orta şiddette bükük diz.

- Şiddetli bükük diz.
Tüm bu gruplarda eklem hareket açıklı̆̆, kurvet, selektif motor kontrol ve spastisite farklı oranlarda etkilenir. Özellikle hamstring kas grubundaki sertlik zaman içerisinde dizdeki fleksiyon miktarını daha da arttırır. Yürüyüş sırasında kuadriseps kasının antigravite kas gücü yetersizliği ile birlikte, fleksiyon açısı zamanla daha da artar.

\section{Sıçrama Yürüyüşü (Jump Gait)}

Diplejik ve bazı tüm vücut tutulumlu SP'li çocuklarda sagittal düzlemde görülen yürüyüş modelidir. Topuk vuruşunda artmış diz fleksiyonu ve bunu takip eden orta duruş fazında ani diz ekstansiyonu ile görülen yürüyüşs şeklidir. Özellikle basma fazında ayakta ekin, basma fazının erken dönemlerinden başlayan ve geç döneme kadar değişen derecelerde artmış kalça fleksiyonu ile karakterizedir. Pelvis normal sınırlarında ya da anteriora eğilmiş durumdadır. Bu durum alt ekstremitelerdeki fleksör kasların spastisitesinden kaynaklanmaktadır.

\section{Tutuk Diz Yürüyüşü (Stiff Knee Gait)}

Tüm salınım fazı boyunca artmış diz ekstansiyonu görülür. Diz fleksiyonu yapılamaz. Kuadriseps grubunun, özellikle de rektus femoris kasının kontraktürü sonucu olarak ortaya çıkar. Ayrıca erken yaşta yapılan iyatrojenik hamstring uzatma cerrahileri sonrası sıklıkla görüldüğü bildirilmiştir. ${ }^{[18]}$

\section{Ön Diz Ağrısı}

Genellikle patellofemoral eklem patolojisi olarak bilinir. Diz fleksiyonda yürüyen SP'li bireylerde zaman içerisinde patella alta görülür. Bunun sonucunda ortaya çıkan kıkırdak dejenerasyonu ilerleyen yaşlarda ağrıya neden olur. Patellar tendonun sabit çekiş açısı ile birlikte hassasiyet ve patella distalinde yıpranmalar görülür. Bu durum ön diz ağrısının nedeni olarak bilinir. [19]

\section{Dizde Dejeneratif Artrit}

Yirmi dereceden fazla görülen diz fleksiyon kontraktürü, erişkin dönemde dejeneratif artrite neden olur. Dereceli bir şeklide spastisitenin artması, azalmış kas aktivitesi ve eklem hareket açıklı̆ı ile birlikte ortaya çıkan kas imbalansı, eklemin anormal kuvvetlere maruz kalmasına neden olur. Genellikle semptomlar 35-40 yaşında ortaya çıkar. Esnekliğin kaybolması ve dizilimin bozulması ile birlikte semptomlar daha da artar. ${ }^{[20]}$

\section{SEREBRAL PALSIDE GÖRÜLEN DIZ PROBLEMLERINDE DEĞERLENDIRME}

\section{Kas İskelet Sistemi Muayenesi}

Aktifve pasif eklem hareket açıklığı, kas kuvveti, spastisite, yürüyüş gibi parametrelerin değerlendirilmesini 
içerir. Aksiyel kemik deformiteleri, kapsüler eklem kontraktürleri ve kaslardaki dinamik kısalmalar ayırt edilmelidir.

Patellanın patellofemoral boşlukta kayma miktarı diz tam fleksiyon ve ekstansiyonda değerlendirilmelidir. Hamstringlerdeki spastisite ve uzunluk popliteal açı ile değerlendirilir. Hasta sırt üstü yatar pozisyonda iken kalça ve diz $90^{\circ}$ fleksiyonda konumlandırılır. Dizin ekstansiyona getirilmesi ile birlikte tibia ile vertikal düzlem arasında kalan açı popliteal açıyı gösterir. Kısıtlılık $20^{\circ}$ 'ye kadar ise normal kabul edilir. ${ }^{[21]}$

\section{Duncan Ely testi}

Rektus femoris kasının spastisitesini ve kalçanın gizli fleksiyon kontraktürünü değerlendirir. Çocuk yüzüstü pozisyonda kalça ve diz ekstansiyonda olacak şekilde yatar. Test edilen taraftaki rektus femorisi germek için diz eklemi pasif fleksiyona getirilir. Eğer o taraftaki rektus femoriste spastisite yoksa kalça yatağın üzerinde kalırken, spastisite olması durumunda dizin fleksiyonu ile birlikte kalça yataktan yükselir. ${ }^{[22]}$

Fleksiyon kontraktürü, hasta sırt üstü yatarken değerlendirilir. Dizin aşağı doğru itilmesi ile $0^{\circ}$ 'lik ekstansiyon sağlanamıyor ise hamstringde kısalma veya posterior kapsülde kontraktür varlığı düşünülür.

\section{Silfverskiöld testi}

Triseps surae kasındaki tonus artışını ve kısalmayı değerlendirir. Soleus ve (diz fleksiyonda dorsifleksiyon), gastroknemius (diz ekstansiyonda dorsifleksiyon) kaslarını ayırt etmeyi sağlar. Sırtüstü posizyonda yatarken, ayağın düzgün aksiyel dizilimi sağlandıktan sonra ayak bileği eklemi önce diz $90^{\circ}$ fleksiyonda sonra diz ekstansiyonda iken pasif dorsifleksiyona getirilir. Eğer diz fleksiyonda iken dorsifleksiyon derecesi, diz ekstansiyonda olana kıyasla daha fazla ise, gastroknemiusun kontraktüre soleustan daha fazla katkıda bulunduğu söylenebilir.

\section{Radyografi}

Radyografik değerlendirme, SP'li hastalarda patellar anormallikler, aksiyel deformiteler, büyüme plaklarının gözlenmesi, kemik ile kartilaj doku arasındaki uyumsuzlukları görmek ve özellikle suprakondiler bölgedeki patolojik kırıkları tespit etmek amacıyla rutin olarak kullanılmalıdır. Daha ileri değerlendirmeler için manyetik rezonans veya bilgisayarlı tomografi görüntülemelerinden yararlanılabilir. Özellikle diz problemlerine bağlı görülen fonksiyonel yürüyüş bozukluklarını değerlendirmek ve müdahale programını oluşturmak amacıyla video kayıt yöntemleri de kullanılır.

\section{Üç Boyutlu Yürüyüş Analizi}

Üç boyutlu yürüyüş analizi, diz problemlerinde cerrahi karar verme süreci açısından oldukça önemlidir. ${ }^{[23,24]}$ Klinik olarak cerrahiye karar verme veya cerrahiyi erteleme ya da iptal etmeye yardımcı olur.

\section{DiZ PROBLEMLERINDE TEDAVI PRENSIPLERi}

Kaslarda görülen zayıflık ve spastisite, fonksiyonel bozukluklara neden olur. Sonucunda, motor gelişimde gerilik ve kompansatuvar değişiklikler, büyüme, eklem subluksasyonu/dislokasyonu ve ağrıya bağlı olarak kas ve yumuşak dokularda ikincil deformiteler gelişir. ílerleyici diz fleksiyon kontraktürünün ortopedik izlem ile birlikte erken dönemde takip altına alınması oldukça önemlidir. Klinik ortopedik muayene ile birlikte artan kas tonusu veya azalmış eklem hareket açıklığı değerlendirilerek, uygulanacak medikal ve/veya cerrahi yaklaşıma karar verilir. Ameliyat öncesi ve sonrası dönemde, fizyoterapi ve rehabilitasyon açısından değerlendirilerek uygun tedavi programının oluşturulması gereklidir.

\section{Fizyoterapi ve Rehabilitasyon}

SP'li bir çocukta birçok gelişim alanı ile ilgili problemler görülse de, temel problemin lokomosyon ile ilgili olduğu bilinir. Bebeklik döneminden başlayarak erişkin döneme kadar geçen sürede hedef her zaman, SP'li bireyin fonksiyonel kapasitesinin izin verdiği ölçüde kendi çevresinde ve yaşadığı çevresel koşullarda bağımsız olmasının sağlanmasıdır. Çocuklar ve aileler için özgün hedefler belirlenirken, çocuğun ve ailenin beklentileri, öncelikleri, değerleri, ihtiyaçları ve istekleri göz önünde bulundurulmalıdır. Hedef belirleme interaktif bir süreçtir. Sonuçlar sürekli değerlendirilmeli, tedavi hedeflerinde oluşturulması gereken değişiklikler göz önünde tutulmalıdır.

Fizyoterapi ve rehabilitasyonun amaçları;

a) normal motor gelişimi desteklemek,

b) kas kuvvetini korunma ve arttırmak,

c) fonksiyonel hareket yeteneğini korunma ve arttırmak,

d) postüral kontrolü geliştirmek,

e) Hareket kalitesini arttırmak,

f) eklem limitasyonları, kontraktürler, deformiteler, tonus problemleri ve skolyoz gibi kas-iskelet sistemi bozukluklarını önlemek,

g) günlük yaşam aktivitelerinde bağımsızlığı sağlamak,

h) yardımcı araç, gereç ve cihaz ihtiyaçlarını belirlemek ve

i) diğer tıbbi, medikal ve cerrahi uygulamaları desteklemeyi içerir. ${ }^{[25,26]}$ 
Fizyoterapi uygulamalarında, bireysel farklılıklar ve klinik durum gözetilerek günlük yaşam becerilerini destekleyici ve fonksiyonel yaklaşımlara biyomekanik prensipler doğrultusunda yer verilmesi önemlidir. Gerekli görülen durumlarda yardımcı araç-gereç ve ekipman kullanımına yer verilerek, bireyin günlük yaşamda maksimum bağımsızlık seviyesini kazanması hedeflenir. ${ }^{[27]}$

Kas tonusunun ve spastisitenin azalması için manuel terapi yöntemleri, germe ve kuvvetlendirme egzersizlerinin yeri büyüktür. Özellikle fonksiyonel pozisyonlarda aktif ve/veya pasif uygulanan germe egzersizlerinin, kasın dinamik kısalmasını engellemede kullanılması gerekir.

Cerrahi öncesi ve/veya sonrası, özellikle kuadriseps femoris kasının kontraktibilitesini arttırmak amacıyla, farklı elektrik stimülasyon yöntem ve tekniklerinden yararlanılabilir. Hatta, aktif hareket ile birlikte uygulanan süperempoze elektrik stimülasyonu son yıllarda yaygın olarak kullanılmaktadır. ${ }^{[28]}$

SP'li bireylerin ayakta durma, yürüme gibi fonksiyonları gerçekleştirmeleri ve günlük yaşamda bağımsızlıklarını kazanmalarında kas kuvvetinin önemi büyüktür. Kas kuvvetlendirme için fonksiyonel egzersizler, manuel rezistif yöntemler, propriyoseptif nöromusküler fasilitasyon teknikleri ve elektrofiziksel ajanlardan yararlanılabilir. Kurvetlendirmeler sırasında fonksiyonun ön planda tutulduğu spesifik kas kuvvetlendirme yöntemlerine yer verilirken, kas lifi tipinin özellikleri mutlaka göz önünde bulundurulmalıdır.

\section{ORTEZLER}

SP'de ortezlemenin; fonksiyonu arttırmak, kontraktür ve deformite gelişimini önlemek, ekstremiteleri fonksiyonel pozisyonda tutmak, ekstremiteleri ve bedeni stabilize etmek, zayıf kas fonksiyonlarını desteklemek, spastisiteyi azaltmak ve ameliyat sonrası ekstremiteyi korumak gibi pek çok amacı vardır.

SP tanılı çocuklarda kullanılan ortezlerin amaçları şu şekilde özetlenebilir:

a) Kas dengesizliği nedeni ile gelişen ve ilerleyici karakterdeki diz eklem deformitelerinin oluşumunu engellemek ve gelişmesi durumunda şiddetini azaltmak.

b) Spastisite ve motor gelişim yetersizliği nedeniyle diz ekstansiyonunu etkin bir şekilde gerçekleştiremeyen çocukların fonksiyonlarını desteklemek ve yürüyüşte meydana gelen normalden sapmaları azaltmak.

c) Diz fleksiyon kontraktürünü engellemek.

d) Ameliyat sonrası yapılan cerrahi işlemi korumak ve desteklemek. ${ }^{[29,30]}$

\section{Ayak - Ayak Bileği Ortezleri (AFO-DAFO)}

AFO ve DAFO'lar ayak ve ayak bileğini kontrol etmek için kuvvet uygularken, tasarımına göre değişmekle birlikte, indirekt olarak kalça ve diz eklemlerini stabilize etmek için de kullanılabilmektedir. Eklemli ve/veya eklemsiz AFO/DAFO'lar kaba motor fonksiyon sınıflama sistemi (GMFCS)'ne göre I düzeyindeki çocuklarda yürüyüş üzerinde etkili olurken, kuadriparezik çocuklarda çıplak ayak ile yürüyüşle kıyaslandığında enerji tüketiminde belirgin derecede azalma sağladığı görülmüştür. Ayrıca, bu iyileşmenin hem duruş hem de sallanma fazında etkili olduğu görülmüştür. ${ }^{[31]}$

Duruş fazında aşırı diz fleksiyonu ve dorsifleksiyon görülen diparetik çocuklarda çocuklarda yer reaksiyon ortezi de eklemsiz AFO/DAFO'ya alternatif olarak kullanılabilir. Duruş sırasında tibianın öne yer değiştirmesini önler ve kuadriseps kası tarafından oluşturulması gereken ekstansör momenti yaratır. SP'li çocuklarda bükük diz yürüyüşü (duruş fazında artmış diz fleksiyonu ve ayak bileği dorsifleksiyonu) olduğu durumda kullanilır. Yer reaksiyon ortezleri genellikle $10^{\circ}$ 'den az olan diz ve kalça fleksiyon deformitelerinde önerilirken, $20^{\circ}$ 'den fazla olan fleksiyon kontraktürlerinde kullanımları uygun değildir. ${ }^{[32,33]}$

\section{Diz - Ayak - Ayak Bileği Ortezleri (KAFO)}

Çoklu seviye alt ekstremite operasyonlarından sonra, zayıf kasları desteklemek ve eklem hareket genişliğini korumak, duruş veya yürüyüşte antigravite kontrolü sağlanacak şekilde diz ekstansiyonunu arttırmak, hiperekstansiyonu kontrol etmek amacıyla kullanılır. ${ }^{[34]} \mathrm{Bu}$ durumlarda öncelikli olarak AFO'lar tercih edilir. Yeterli olmadığı durumlarda KAFO kullanılmalıdır. Ayrıca, cerrahi öncesi veya sonrası antispastik pozisyonu elde etmek amacıyla kullanılır.

\section{BOTULINUM TOKSIN A UYGULAMASI}

Spastisiteyi azaltmak amacıyla yaygın olarak kullanılan bir yöntem olup, diğer tedavi yöntemleri ile birlikte kullanılması önerilmektedir. ${ }^{[35,36]}$ Örneğin; spastik ekin problemi olan çocuklarda yapılan seri alçılamanın, sadece botulinum toksin A uygulamasından daha etkin olduğu gösterilmiştir. ${ }^{[37]}$ Bükük diz ve gergin diz yürüyüşünde hamstring, rektus femoris ve gastroknemius kaslarına yapılan çok seviyeli botulinum toksin A enjeksiyonu tedavi açısından önemlidir. Botulinum toksin A uygulaması sonrası her SP'li birey için hazırlanmış egzersiz, ortez, seri alçılamayla birlikte yapılan ilaç tedavisi ile, etkinin çok daha yüksek olduğu bildirilmiştir. Bireyin motor performansına göre yapılan enjeksiyonlarla duyu-motor gelişim desteklendiği gibi, hamstring kaslarındaki gerginliğin azaltılması ile 
yürüyüş parametreleri iyileşir. Her ne kadar uzun dönem sonuçları kesin olarak bilinmese de; güçsüzlük, konuşma problemleri, ağrı ve ödem, botulinum toksin A'nın bilinen yan etkileridir. ${ }^{[38,39]}$

\section{CERRAHI YÖNTEMLER}

SP'li bireylerin cerrahi sürecine karar vermede, fonksiyonel problemlerin en erken dönemde tespit edilmesi önemlidir. İyi bir analiz ile patolojinin nedeni saptanmalı ve cerrahi için uygun zaman belirlenmelidir. Özellikle iletişim problemi olan SP'li bireylerde; spastisite, kalkaneal bölgede cilt bütünlüğünde bozulmalar, ilerleyen kas zayıflığı, duyu-motor problemleri, yanlış cihaz ve yetersiz rehabilitasyon durumları gözden kaçmamalıdır.

Kas içi mediyal hamstring uzatma: Hamstring spastisitesine bağlı olarak görülen dinamik diz deformitelerinde kullanılır. Hamstring kaslarının uzatılması ile dik postür sağlanırken, enerji tüketimi azalır, kas gücü korunur ve kas fonksiyonu restore edilmiş olur. ${ }^{[40,41]}$

Perkütan mediyal hamstring tenotomi: Minimal invaziv bir yöntem olup, seçilmiş hasta grubunda açık uzatmaya göre daha üstün olabilir.

Kas içi biseps femoris uzatma: Peroneal sinirin yaralanmamasına dikkat edilmelidir.

Hamstring ve biseps femoris kası tenotomisi: Yürüme potansiyeli olmayan SP'li bireylerde kaslarda görülen aşırı kısalma oturmayı da bozabileceği gibi, kalçadaki adduktor ve abduktor deformiteye bağlı olarak "windswept" deformitesine neden olur. Ortaya çıkabilecek bu bozukluğu önlemek amacıyla yararlanılan bir yöntemdir.

Hamstring kaslarının proksimal tenotomisi: Hamstring kasları iskial tuberositastaki orijin noktalarından gevşetilir. Özellikle artmış posterior pelvik tilt ile birlikte görülen aşırı ve/veya tekrarlı hamstring kısalıklarında endikedir.

Rektus femoris gevşetme: Artmış rektus femoris gerginliği sallanma fazında diz fleksiyonunun azalmasına neden olur. Kasın proksimalinden ve/veya distalinden gevşetme yapılabilir.

Diz ekleminde posterior kapsül gevşetme: Kalça ekstansiyonu ve ayak dorsifleksiyonu serbest olan, sabit diz fleksiyonu problemlerinde kullanılan bir yöntemdir. Hamstring ve biseps kaslarının gevşetilmesi ile birlikte diz ekleminin posterir kapsülotomisini içerir.

Distal suprakondiler femoral ekstansiyon osteotomi: Açık veya kapalı redüksiyon ile sabit diz fleksiyon deformitelerinde, çok seviyeli cerrahinin bir parçası olarak kullanılan bir yöntemdir.
Sonuç olarak; SP'li bireylerde görülen diz problemleri çok seviyeli olarak irdelenmelidir. Müdahale yöntemlerine; biyomekanik analiz, musküloskeletal muayene, yaş, kaba motor fonksiyon seviyesi ve günlük yaşam aktiviteleri göz önünde bulundurularak karar verilmelidir.

\section{KAYNAKLAR}

1. Rosenbaum P, Paneth $N$, Leviton A, Goldstein M, Bax MA. The definition and classification of cerebral palsy. Dev Med Child Neurol 2007;49:1-44.

2. Günel M. Rehabilitation of children with cerebral palsy from a physiotherapist's perspective. Acta Orthop Traumatol Turc 2009;43(2):173-80. Crossref

3. Verschuren O, Smorenburg ARP, Luiking Y, Bell K, Barber $L$, Peterson MD. Determinants of muscle preservation in individuals with cerebral palsy across the lifespan: a narrative review of the literature. J Cachexia Sarcopenia Muscle 2018;9(3):453-64. Crossref

4. Peterson MD, Gordon PM, Hurvitz EA, Burant CV. Secondary muscle pathology and metabolic dysregulation in adults with cerebral palsy. Am J Physiol Endocrinol Metab 2012;303(9);E1085-93. Crossref

5. Weber MA, Pavin M, Gremski C. Medical secondary conditions among adults with cerebral palsy. Arch Phys Med Rehabil 1995;76:1055-62.

6. Reilly S, Skuse D. Characteristics and management of feeding problems of young children with cerebral palsy. Dev Med Child Neurol 1992;34(5):379-88. Crossref

7. Wandel JA. Cerebral Palsy, Chap. 17. In: Solomon J, O'Brien J. Pediatric Skills for Occupational Therapy Assistants, 4th ed. St Louis: CV Mosby; 2015. p.115-6.

8. Carlberg EB, Hadders-Algra M. Postural control: A key issue in developmental disorders, 1st ed. London: MacKeith Press, 2008.

9. Woollacott M. H, Burtner P, Jensen J, Jasiewicz J, Roncesvalles $N$, Sveistrup $H$. Development of postural responses during standing in healthy children and in children with spastic diplegia. Neurosci Biobehav Rev 1998;22(4):583-9. Crossref

10. Knutsson E, Richards C. Different types of disturbed motor control in gait of hemiparetic patients. Brain 1979;102(2):405-30. Crossref

11. Kerrigan DC, Deming LC, Holden MK. Knee recurvatum in gait: a study of associated knee biomechanics. Arch Phys Med Rehabil 1996;77(7):645-50. Crossref

12. Simon SR, Deutsch SD, Nuzzo RM, Mansour MJ, Jackson $\mathrm{JL}$, Koskinen M, Rosenthal RK. Genu recurvatum in spastic cerebral palsy. Report on findings by gait analysis. J Bone Joint Surg Am 1978;60(7):882-94. Crossref

13. Gugenheim JJ, Rosenthal RK, Simon SR. Knee flexion deformities and genu recurvatum in cerebral palsy: roentgenographic findings. Dev Med Child Neurol 1979;21(5):563-70. Crossref

14. Rosenthal RK, Deutsch SD, Miller W, Schumann W, Hall JE. A fixed-ankle, below-the-knee orthosis for the management of genu recurvation in spastic cerebral palsy. J Bone Joint Surg Am 1975;57(4):545-7. Crossref

15. Perry J, O'Brien JP, Hodgson AR. Triple tenodesis of the knee. A soft-tissue operation for the correction of paralytic genu recurvatum. J Bone Joint Surg Am 1976;58(7):978-85. Crossref 
16. Dhawlikar SH, Root L, Mann RL. Distal lengthening of the hamstrings in patients who have cerebral palsy. Long-term retrospective analysis. J Bone Joint Surg Am 1992;74(9):138591. Crossref

17. Rozumalski A, Schwartz MH. Crouch gait patterns defined using k-means cluster analysis are related to underlying clinical pathology. Gait Posture 2009;30(2):155-60. Crossref

18. Ellington MD, Scott AC, Linton J, Sullivan E, Barnes D. Rectus Femoris Transfer Versus Rectus Intramuscular Lengthening for the Treatment of Stiff Knee Gait in Children With Cerebral Palsy. J Pediatr Orthop 2018;38(4):e213-8. Crossref

19. Senaran H, Holden C, Dabney KW, Miller F. Anterior knee pain in children with cerebral palsy. J Pediatr Orthop 2007;27(1):12-6. Crossref

20. Böhm H, Hösl M, Schwameder H, Döderlein L. Stiff-knee gait in cerebral palsy: how do patients adapt to uneven ground? Gait Posture 2014;39(4):1028-33. Crossref

21. Ten Berge SR, Halbertsma JP, Maathuis PG, Verheij NP, Dijkstra PU, Maathuis KGB. Reliability of popliteal angle measurement: a study in cerebral palsy patients and healthy controls. J Pediatr Orthop 2007;27(6):648-52. Crossref

22. Dormans JP, Pellegrino L. Caring for Children with Cerebral Palsy, 2nd ed. Baltimore: PH. Brookes Publishing Co; 1998.

23. Gough M, Shortland AP. Can clinical gait analysis guide the management of ambulant children with bilateral spastic cerebral palsy? J Pediatr Orthop 2008;28(8):879-83. Crossref

24. Gough M, Schneider P, Shortland AP. The outcome of surgical intervention for early deformity in young ambulant children with bilateral spastic cerebral palsy. J Bone Joint Surg Br 2008;90-B(7):946-51. Crossref

25. Fonseca PR Jr, Franco de Moura RC, Galli M, Santos Oliveira C. Effect of physiotherapeutic intervention on the gait after the application of botulinum toxin in children with cerebral palsy: systematic review. Eur J Phys Rehabil Med 2017;54(5):757-65. Crossref

26. Papavasiliou AS. Management of motor problems in cerebral palsy: a critical update for the clinician. Eur J Paediatr Neurol 2009;13(5):387-96. Crossref

27. Elbasan B. Pediatrik Fizyoterapi Rehabilitasyon, 2. baskı. Ankara: İstanbul Tıp Kitabevleri; 2017.

28. Elbasan B, Akaya KU, Akyuz M, Oskay D. Effects of neuromuscular electrical stimulation and Kinesio Taping applications in children with cerebral palsy on postural control and sitting balance. J Back Musculoskelet Rehabil 2018;31(1):49-55. Crossref

29. Lintanf $M$, Bourseul JS, Houx L, Lempereur M, Brochard $S$, Pons C. Effect of ankle-foot orthoses on gait, balance and gross motor function in children with cerebral palsy: a systematic review and meta-analysis. Clin Rehabil 2018;32(9):1175-88. Crossref
30. Aboutorabi A, Arazpour M, Ahmadi Bani M, Saeedi H, Head JS. Efficacy of ankle foot orthoses types on walking in children with cerebral palsy: A systematic review. Ann Phys Rehabil Med 2017;60(6):393-402. Crossref

31. Brehm MA, Harlaar J, Schwartz M. Effect of ankle-foot orthoses on walking efficiency and gait in children with cerebral palsy. J Rehabil Med 2008;40(7):529-34. Crossref

32. Rogozinski BM, Davids JR, Davis RB 3rd, Jameson GG, Blackhurst DW. The efficacy of the floor-reaction ankle-foot orthosis in children with cerebral palsy. J Bone Joint Surg Am 2009;91(10):2440-7. Crossref

33. Romkes J, Hell AK, Brunner R. Changes in muscle activity in children with hemiplegic cerebral palsy while walking with and without ankle-foot orthoses. Gait Posture 2006;24(4):46774. Crossref

34. Maas JC, Dallmeijer AJ, Oudshoorn BY, Bolster EAM, Huijing PA, Jaspers RT, Becher JG. Measuring wearing time of knee-ankle-foot orthoses in children with cerebral palsy: comparison of parent-report and objective measurement. Disabil Rehabil 2018;40(4):398-403. Crossref

35. Molenaers G, Fagard K, Van Campenhout A, Desloovere $\mathrm{K}$. Botulinum toxin A treatment of the lower extremities in children with cerebral palsy. J Child Orthop 2013;7(5):383-7. Crossref

36. Goldstein $M$. The treatment of cerebral palsy: What we know, what we don't know. J Pediatr 2004;145(2 Suppl):S42-6. Crossref

37. Glanzman AM, Kim H, Swaminathan K, Beck T. Efficacy of botulinum toxin $A$, serial casting, and combined treatment for spastic equinus: a retrospective analysis. Dev Med Child Neurol 2004;46(12):807-11. Crossref

38. Kay RM, Rethlefsen SA, Fern-Buneo A, Wren TA, Skaggs DL. Botulinum toxin as an adjunct to serial casting treatment in children with cerebral palsy. J Bone Joint Surg Am 2004;86$A(11): 2377-84$. Crossref

39. Koman LA, Mooney JF 3rd, Smith BP, Walker F, Leon JM. Botulinum toxin type $A$ neuromuscular blockade in the treatment of lower extremity spasticity in cerebral palsy: a randomized, double-blind, placebo-controlled trial. BOTOX Study Group. J Pediatr Orthop 2000;20(1):108-15. Crossref

40. Adolfsen SE, Ounpuu S, Bell KJ, DeLuca PA. Kinematic and kinetic outcomes after identical multilevel soft tissue surgery in children with cerebral palsy. J Pediatr Orthop 2007;27(6):658-67. Crossref

41. Lovejoy SA, Tylkowski C, Oeffinger D, Sander L. The effects of hamstring lengthening on hip rotation. J Pediatr Orthop 2007;27(2):142-6. Crossref 